\title{
Comparing and Contrasting First and Second Language Acquisition
}

\author{
PhD llda Poshi \\ MSc Fjona Çukani
}

\section{Doi:10.5901/mjss.2013.v4n10p56}

\section{Abstract}

The ways in which an individual characteristically acquires, retains, and retrieves information in secondary language collectively term the individual's learning ability. This paper will mainly treat the difference between a child and an adult language acquisition.Determining the difference between a child and an adult foreign language acquisition best depends on a number of variables: the learner's age, aptitude, and motivation; the amount of time available for instruction; and the difference between the native and the foreign language. For young children, starting early can lead to mastery of a foreign language with no long-term detriment to their grasp of English. Older students and adults, on the other hand, need a judicious mixture of practice and communication. We are looking at child first language acquisition and adult second language acquisition because they both seem most relevant to our lives right now - as college students who have most definitely mastered our first language at a young age, and are mostly likely attempting to master our second as adults. On the surface, one would look at child first language acquisition and adult second language acquisition and see similarities. The theory of Universal Grammar as developed in the tradition of generative grammar by Noam Chomsky was adopted. In each case, the learner first learns how to make basic sounds, then words, phrases and sentences; and as this learning continues the sentences become more and more complex. However, when one looks at the outcomes of these two types of acquisition, the differences are dramatic. The child's ability to communicate in the target language far surpasses that of the adult. In this paper differences in these two processes that most always produce such different outcomes will be explored.

\section{Introduction}

In our everyday lives, the origin of our ability to communicate is usually not often taken into consideration. One doesn't think about how every person has, or rather had at one time, an innate ability to learn a language to total fluency without a conscious effort $-a$ feat that is seen by the scientific community "as one of the many utterly unexplainable mysteries that beset us in our daily lives" (First Language Acquisition). Other such mysteries include our body's ability to pump blood and take in oxygen constantly seemingly without thought, and a new mother's ability to unconsciously raise her body temperature when her infant is placed on her chest. But, a child's first language acquisition is different from these phenomena; different because it cannot be repeated. No matter how many languages are learned later in life, the rapidity and accuracy of the first acquisition is an established motor pattern (Genesee, F. (1988) pg. 101) which can simply not be repeated. This mystery is most definitely why first language acquisition, and subsequently second language acquisition, is such a highly researched topic.

On the surface, one would look at child first language acquisition and adult second language acquisition and see similarities. In each case, the learner first learns how to make basic sounds, then words, phrases and sentences; and as this learning continues, the sentences become more and more complex. However, when one looks at the outcomes of these two types of acquisition, the differences are dramatic. The child's ability to communicate in the target language far surpasses miraculously that of the adult. In this paper, differences in these two processes that most always produce such different outcomes will be explored.

Before this exploration begins, however, I would like to state that I am looking at child first language acquisition and adult second language acquisition because they both seem most relevant to our lives right now - as college students who have most definitely mastered our first language at a young age, and are mostly likely attempting to master our second as adults. One could also look at situations where only one variable changes (e.g. child first vs. child second or child second vs. adult second) but these comparisons are not represented in this paper.

\section{The Criterions}

The first area of difference between first (L1) and second (L2) language learning is input - specifically the quality and quantity of input. It is the idea of the "connectionist model that implies... (that the) language learning process depends on 
the input frequency and regularity" (Macnamara, J. (1975), pg. 71-94). It is here where one finds the greatest difference between L1 and L2 acquisition. The quantity of exposure to a target language a child gets is immense compared to the amount an adult receives. A child hears the language all day every day, whereas an adult learner may only hear the target language in the classroom - which could be as little as three hours a week. Even if one looks at an adult in a total submersion situation the quantity is still less because the amount of one on one interaction that a child gets for example with a parent or other caregiver is still much greater than the adult is receiving. And as Chomsky assesses "Language learning is not really something that the child does, it is something that happens to the child placed in an appropriate environment much as the child's body grows and matures in a predetermined way when provided with appropriate nutrition and environmental stimulation." (Cook, Vivian J. \& Newson, Mark,2007, pg: 204-205). No matter how weird it might sound, the mind is somewhat "equipped" with a mechanism which was settled into the brain beforehand so that it can interpret language experience. Experience does not exist if pre-set knowledge had not been there in first place.

This idea of one on one interaction versus a classroom setting (where an instructor could be speaking to up to twenty, or more students) also ties in with the idea of quality. It is also much easier for a parent or caregiver to engage the child in what he or she is learning. It is hard, however, for a teacher to make the topic being learned relevant to the students' lives. This can lead to a lack of concentration, and a lack of motivation - something that will be visited later.

The next great and obvious difference between L1 and L2 learning is age. A large part of this train of thought is the idea of a "critical period, or the "time after which successful language learning cannot take place" (Gass, Susan M., Larry Selinker. 2001). This time is usually aligned with puberty. This change is significant, "because virtually every learner undergoes significant physical, cognitive, and emotional changes during puberty.

There are three main physical changes one undergoes in regards to language acquisition. The first is the presence of muscular plasticity (psychomotor considerations = related to the development of speech muscles that allow the learner to control complex sounds determining pronunciation and accent.). A child's plasticity goes away at about the age of five. After this age, it is very hard for a learner to fully master authentic pronunciation of a second language. The second change is one's memorization capabilities. It is fairly well known that as a person grows older their ability to hold large amount of information reaches its peak fairly early in life, and then begins to decrease. This is seen most dominantly with very old individuals. The third physical change that occurs is more related to neurology.

"As a child matures into adulthood, the left hemisphere (which controls the analytical and intellectual functions) becomes more dominant than the right side (which controls the emotional functions)." (First and Second Language Acquisition).

This idea is called the Lateralization Hypothesis. The significance these specific neurobiological changes have on language learning will be discussed below (Genesee, F. (1988), pg. 81-112).

The one advantage adults seem to have over children is their cognitive ability ( $=$ the learner's intellectual development). Adults are better able to benefit from learning about structure and grammar or even deductive thinking. Unfortunately, this slight advantage in ability does not help adult second language acquisition in general. In fact, this ability almost hinders them in that they analyze too much. Specifically, they cannot leave behind what they know about their first language, which leads to a tendency to overanalyze and to second-guess what they are learning.

The final area that puberty changes is within the emotional or affective realm. Motivation is much affected by emotional change. A child's motivation is simple. In order to communicate and to be a part of family and society the child must master the target language. This motivation is quite weighty, especially when compared to the motivation that adults have, or rather, must find. Adult motivations usually fall into one of two categories: "integrative motivation (which encourages a learner to acquire the new language in order to become closer to and/or identify themselves with the speakers of the target language) or instrumental motivation (which encourages a learner to acquire proficiency for such practical purposes as becoming a translator, doing further research, and aiming for promotion in their career)" (LarsenFreeman, D. and Long, M.H. (1991). Either one of these types of motivation must be prevalent for successful acquisition to take place.

The final change that takes place, and changes language learning has to do with egocentricity. Children are naturally egocentric. While learning their language they are not afraid to make mistakes, and in general, they do not feel abashed when they are corrected. Also, their thoughts usually do not surpass their language ability. Adults, on the other hand usually suffer form a fairly large amount of language learning anxiety. Adults often "feel frustrated or threatened in the struggle of learning a different language" (Holland, R. and Shortall, T. (1997). Mistakes are seen more as failures then as opportunities for growth. "The adult learner may also feel greatly frustrated, for being only able to express their highly complex ideas at a discourse level of an elementary school pupil", (Larsen-Freeman, D. and Long, M.H. (1991). These new emotions leave an adult learner in a slightly helpless position, unable to regain the egocentricity of their 
childhood, which is just one more hindrance in a line of many. In order to become a successful learner, therefore, adult learners must overcome these inhibitions and frustrations, and cross the bridge to acquire a second identity (Brown, $\mathrm{H}$. D. (1994) Principles of Language Learning and Teaching: 63), or emphatic capacity in the new language.

\section{The Results}

Although the desired outcomes of child first language acquisition and adult second language acquisition are exactly the same, the actual outcomes are in reality quite different. Factors such as motivation, quality and quantity of input and a lack of egocentrism, among many other factors such as: the learner's ability to make conscious something that he uses sub-consciously or something he has learned to use sub-consciously many years ago, his native language and exposure to the foreign language, his innate ability to embrace or assimilate a foreign language sound/pattern and the learner's speech habit, - will forever stand in the way of adult second language learning. In conclusion, because of so many varying factors, both the processes and outcomes of child first language acquisition and adult second language acquisition are extremely different, and are only connected by a common goal - i.e. to acquire the best and the most they can from the language learning process.

\section{References}

Brown, H. D. (1994) Principles of Language Learning and Teaching (3rd edition) New Jersey: Prentice Hall.

Comparing and Contrasting First and Second Language Acquisition

(http://www.literature.freeservers.com/image_polat/ccfsla.html)

Cook, V.J. 1973. The comparison of language development in native children and foreign adults. IRAL XI/1, 13-28, online version

Cook, V. (1969) 'The Analogy Between First and Second Language Learning'. International Review of Applied Linguistics, 7: pg. 207216. ,on-line version

Cook, Vivian J. \& Newson, Mark (2007) Chomsky's Universal Grammar: An Introduction (3rd edition), Blackwell Publishing, pg. 185-238

Ellis, R. (1997) Second Language Acquisition. Oxford: Oxford University Press.

First and second language acquisition (http://homepage.ntlworld.com/vivian.c/SLA/L1\%20and\%20L2.htm)

First Language Acquisition (http://www.csun.edu/ galasso/lang1.htm)

Gass, Susan M., Larry Selinker. (2001) Second Language Acquisition. London: Lawrence; Erlbaum Associates Publishers.

Genesee, F. (1988) 'Neuropsychology and Second Language Acquisition'. In L.M. Beebe (1988). pg: 81-112.

Holland, R. and Shortall, T. (1997) Classroom Research and Research Methods. University of Birmingham MA TEFL/TESL Open Learning Programme.

Larsen-Freeman, D. and Long, M.H. (1991) An Introduction to Second Language Acquisition Research. London: Longman.

Lightbown, P.M. and Spada N. (1999) How Languages are Learned (2nd edition) Oxford: Oxford University Press.

Macnamara, J. (1975) 'Comparison Between First and Second Language Learning'. Working Papers on Bilingualism, 7: pg: 71-94.

Scovel, T. (1988) 'Multiple Perspectives Make Singular Teaching'. In L.M. Beebe (1988) , pg: 169-190. 